\title{
Supplementary Information for Graphene-Sealed Flow Cells for In Situ Transmission Electron Microscopy of Liquid Samples
}

Gabriel Dunn, Vivekananda P. Adiga, Thang Pham, Christopher Bryant, Donez J. HortonBailey, Jason N. Belling, Ben LaFrance, Jonathan A. Jackson, Hamid Reza Barzegar, Jong Min Yuk, Shaul Aloni, Michael F. Crommie and Alex Zettl

The fabrication process for the GFC is illustrated schematically in Table 1. For concreteness we describe here the fabrication and testing of GFCs in which the top window is graphene and the bottom window is very thin $\mathrm{Si}_{3} \mathrm{~N}_{4}$. We utilize two versions of the nanochannel chip, the first with $\mathrm{Si}_{3} \mathrm{~N}_{4}: \mathrm{SiO}_{2}: \mathrm{Si}_{3} \mathrm{~N}_{4}=25 \mathrm{~nm}: 100 \mathrm{~nm}: 25 \mathrm{~nm}$, and the second with $\mathrm{Si}_{3} \mathrm{~N}_{4}: \mathrm{SiO}_{2}$ : $\mathrm{Si}_{3} \mathrm{~N}_{4}=14 \mathrm{~nm}: 70 \mathrm{~nm}: 7 \mathrm{~nm}$. These stacks are deposited onto a $300 \mu \mathrm{m}$ thick 4-inch silicon wafer (100). We pattern the gold electrode using the lift-off technique. Next, we open a window on the backside of the wafer using a plasma etch. This opens up the $\mathrm{SiN} / \mathrm{SiO}_{2} / \mathrm{SiN}$ stack, exposing the silicon underneath. We perform a $\mathrm{KOH}$ etch until the silicon is completely consumed and the $\mathrm{Si}_{3} \mathrm{~N}_{4}$ layer is revealed. Next, we pattern channels in the $\mathrm{Si}_{3} \mathrm{~N}_{4}: \mathrm{SiO}_{2}: \mathrm{Si}_{3} \mathrm{~N}_{4}$. To do this, the channel chip is first spin-coated with two layers of PMMA. We then use electron beam (ebeam) patterning to create an array of individual point exposures spaced $1 \mu \mathrm{m}$ apart which define the eventual locations for holes in the top $\mathrm{Si}_{3} \mathrm{~N}_{4}$ layer. We then create these holes using an $\mathrm{SF}_{6}$ plasma etch. The continuous nanochannel under the array of holes is fomed using a wet buffered hydrofluoric acid (BHF) etch, which removes $\mathrm{SiO}_{2}$ from beneath each hole, leaving a hollow cylindrical chamber in the $\mathrm{SiO}_{2}$. As etching continues, the cylindrical chambers or cavities become interconnected, leading to a continuous channel with headroom between the perforated upper $\mathrm{Si}_{3} \mathrm{~N}_{4}$ layer and the continuous $\mathrm{Si}_{3} \mathrm{~N}_{4}$ layer spaced $70 \mathrm{~nm}$ or $100 \mathrm{~nm}$ below it.

Monolayer graphene is produced using well-established methods. ${ }^{1}$ For multi-layer graphene, we coil copper foil inside a 1-inch diameter quartz tube and anneal it under $200 \mathrm{sccm}$ $\mathrm{H}_{2}$ in vacuum at $1025^{\circ} \mathrm{C}$ for $1 \mathrm{hr}$. We then close the vacuum valve and allow the tube to pressurize to $1 \mathrm{~atm}$ before opening the exhaust valve. $18 \mathrm{sccm} \mathrm{CH} \mathrm{CH}_{4}$ is then introduced in addition to the $200 \mathrm{sccm} \mathrm{H}_{2}$ for a $1 \mathrm{hr}$ growth time. We confirm the graphene thickness to be monolayer or few-layer using Raman spectroscopy, then spin-coat this graphene with PMMA and etch away the copper substrate using a sodium persulphate solution. We wet-transfer the floating PMMA/graphene bilayer onto the channel chip, and subsequently remove the PMMA using either acetone or an annealing process.

The graphene-windowed nanochannel chip described above is mated to a complementary smaller second chip: the top plate. The top plate provides the interface to an external fluid source and drain piping. It is fabricated with a slit and its own fluidic channels. Fabrication steps are shown in table 2. To ensure a leak-free seal when the nanochannel chip and top plate are mated, metals are evaporated onto the bonding surface of each chip to create a soft metal gasket. Using electron beam evaporation, we sequentially add $1 \mathrm{~nm}$ of $\mathrm{Cr}, 10 \mathrm{~nm}$ of $\mathrm{Au}$, and $5 \mu \mathrm{m}$ of indium onto the top plate; and $1 \mathrm{~nm}$ of $\mathrm{Cr}$ and $10 \mathrm{~nm}$ of Au onto the nanochannel chip. The two chips are then press-fit together inside a custom chuck that is a replica of the Poseidon flow cell holder where they will eventually be placed. To bond the two chips together, the force-loaded chuck is heated to $200^{\circ} \mathrm{C}$ for approximately 30 s before being slowly cooled to room temperature. This assembly process in described in table 3. 


\begin{tabular}{|c|c|}
\hline & $\begin{array}{l}300 \mu \mathrm{m} \text { thick, double-side polished, } 4 \text { " Si wafers are used for batch } \\
\text { fabrication of nanochannel chips. }\end{array}$ \\
\hline & $\begin{array}{l}\text { A stack of } \mathrm{Si}_{3} \mathrm{~N}_{4} / \mathrm{SiO}_{2} / \mathrm{Si}_{3} \mathrm{~N}_{4} \text { is deposited by LPCVD to each side } \\
\text { of the wafer. }\end{array}$ \\
\hline - & $\begin{array}{l}\text { Metal contacts }(\mathrm{Au} / \mathrm{Cr}) \text { serving as alignment markers are patterned } \\
\text { and deposited on the top of the chip. }\end{array}$ \\
\hline$m=$ & $\begin{array}{l}\text { A suspended } \mathrm{Si}_{3} \mathrm{~N}_{4} / \mathrm{SiO}_{2} / \mathrm{Si}_{3} \mathrm{~N}_{4} \text { stack is produced (released) by a } \\
\text { backside } \mathrm{KOH} \text { etch after opening up silicon on the backside with } \\
\text { RIE etch. }\end{array}$ \\
\hline 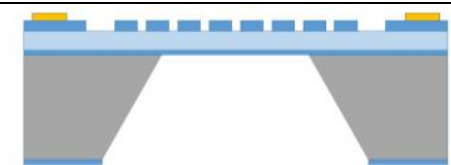 & $\begin{array}{l}\text { The nanochannel is patterned by ebeam point exposures in PMMA } \\
\text { followed by a RIE of the top } \mathrm{Si}_{3} \mathrm{~N}_{4} \text { layer. This is followed by } \\
\text { PMMA strip. }\end{array}$ \\
\hline 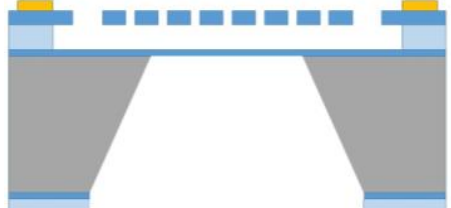 & $\begin{array}{l}\text { The sandwiched } \mathrm{SiO}_{2} \text { is selectively etched away using a BHF etch, } \\
\text { creating a row of interconnected cylindrical cavities which form } \\
\text { the nanochannel. The nanochannel, running left to right, will be } \\
\text { formed within the suspended stack. }\end{array}$ \\
\hline 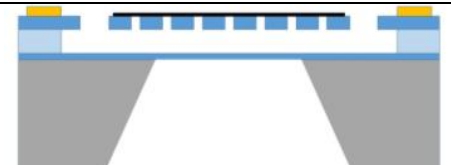 & $\begin{array}{l}\text { Graphene is deposited over the holes in the } \mathrm{Si}_{3} \mathrm{~N}_{4} \text { covering the top } \\
\text { of the nanochannel. The bottom of the nanochannel remains thin } \\
\mathrm{Si}_{3} \mathrm{~N}_{4} \text {. }\end{array}$ \\
\hline 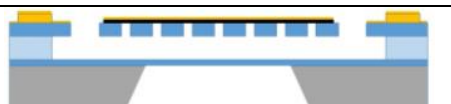 & $\begin{array}{l}\text { A thin layer of gold }(10 \mathrm{~nm}) \text { is deposited on top of the channel as } \\
\text { an Indium bonding promoter. }\end{array}$ \\
\hline
\end{tabular}

Table 1: Fabrication steps for Nano channel chip (Bottom chip). Grey is silicon. Blue is $\mathrm{Si}_{3} \mathrm{~N}_{4}$. Light blue is $\mathrm{SiO}_{2}$. Yellow is gold. 


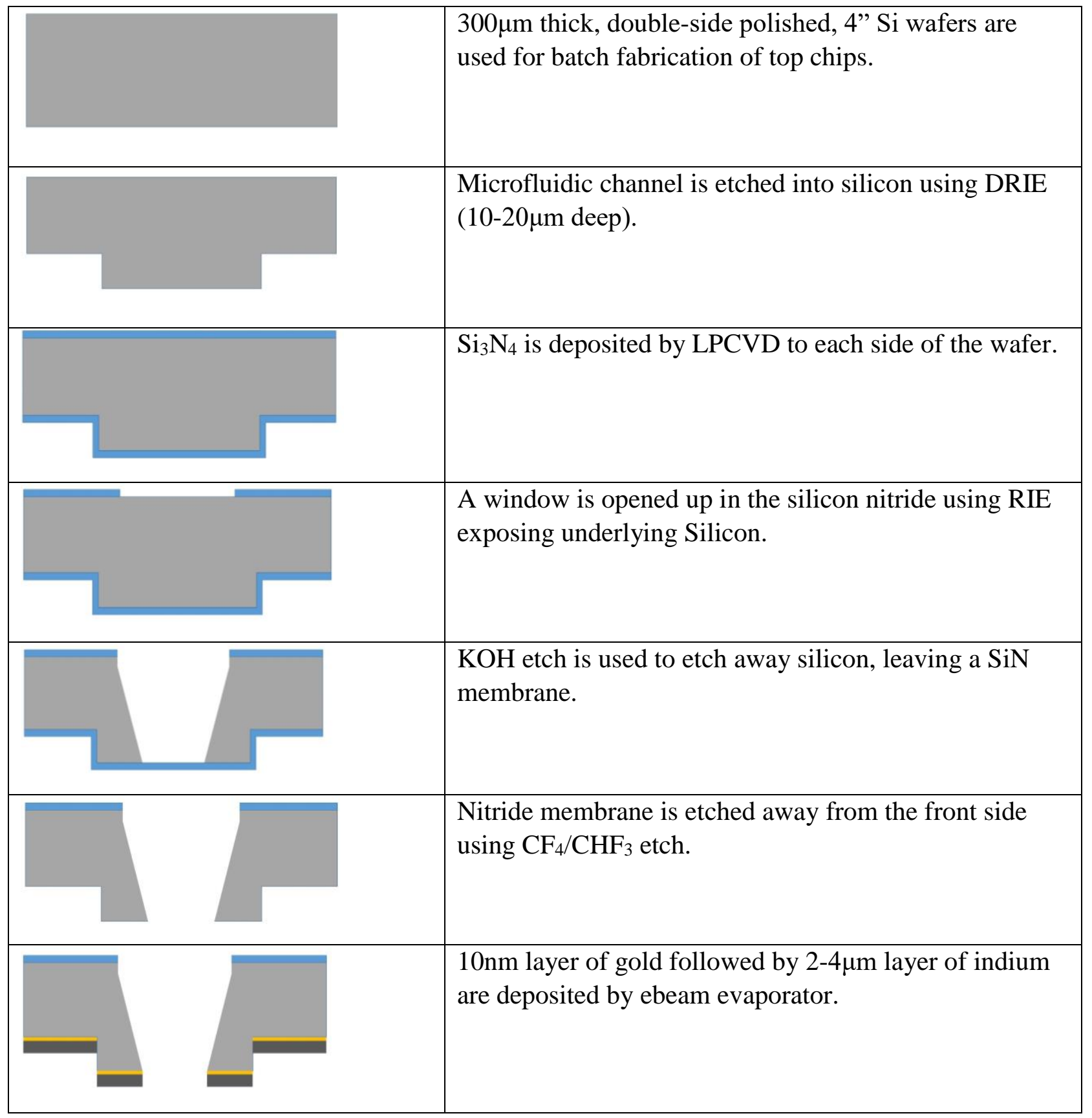

Table 2: Fabrication steps for the top chip. Grey is silicon. Blue is $\mathrm{Si}_{3} \mathrm{~N}_{4}$. Yellow is gold. Dark grey is indium. 


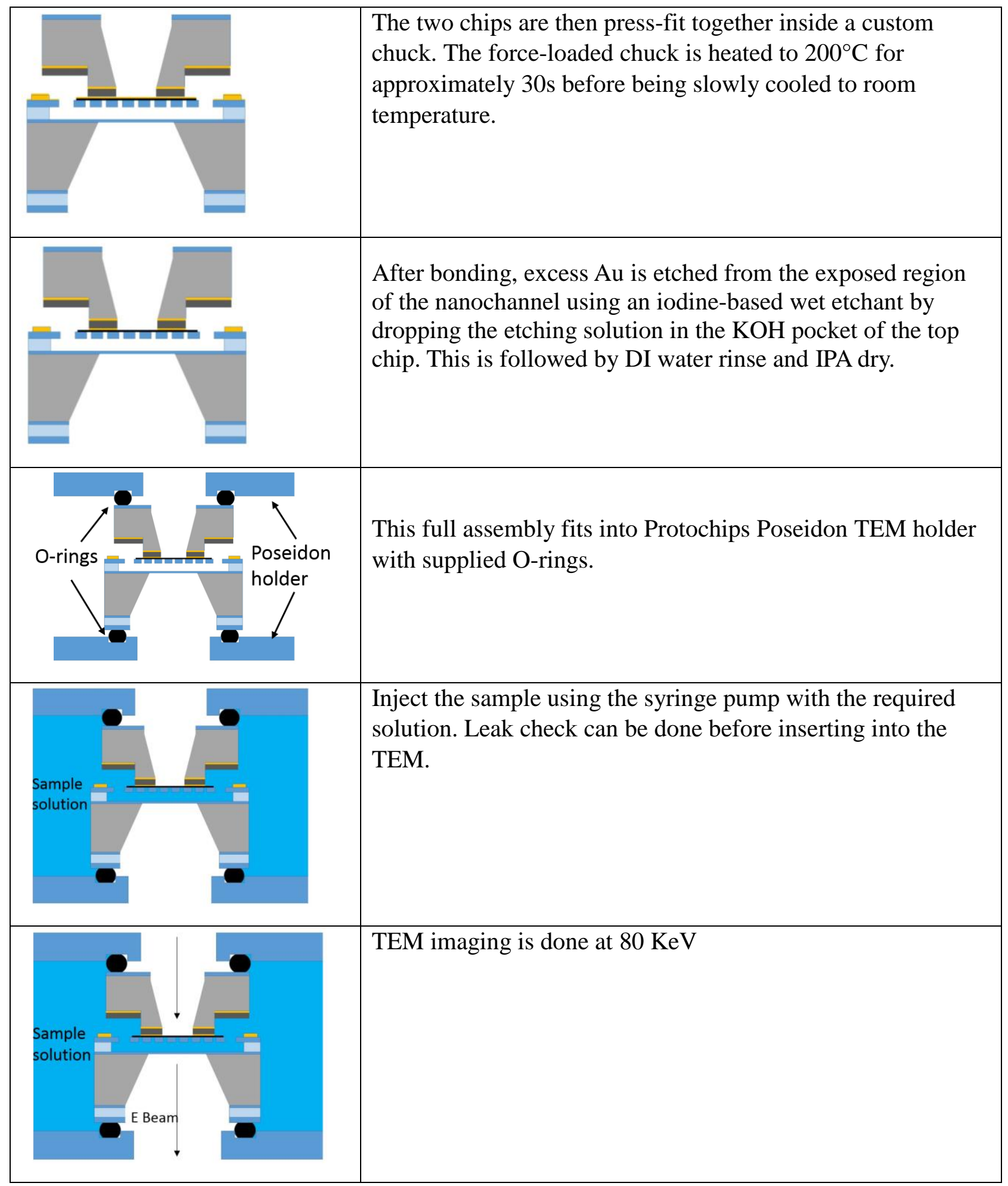

Table 3: Final assembly of the chips and TEM holder. Grey is silicon. Blue is Si3N4. Yellow is gold. Dark grey is Indium. 
This full assembly is compatible with Protochips Poseidon TEM holder. We introduce DI water into the TEM holder for optical imaging using a custom built set up (Figure 4) and leak check the channel before introduction to the high vacuum TEM environment. Then we introduce the sample solution just before loading into the TEM.

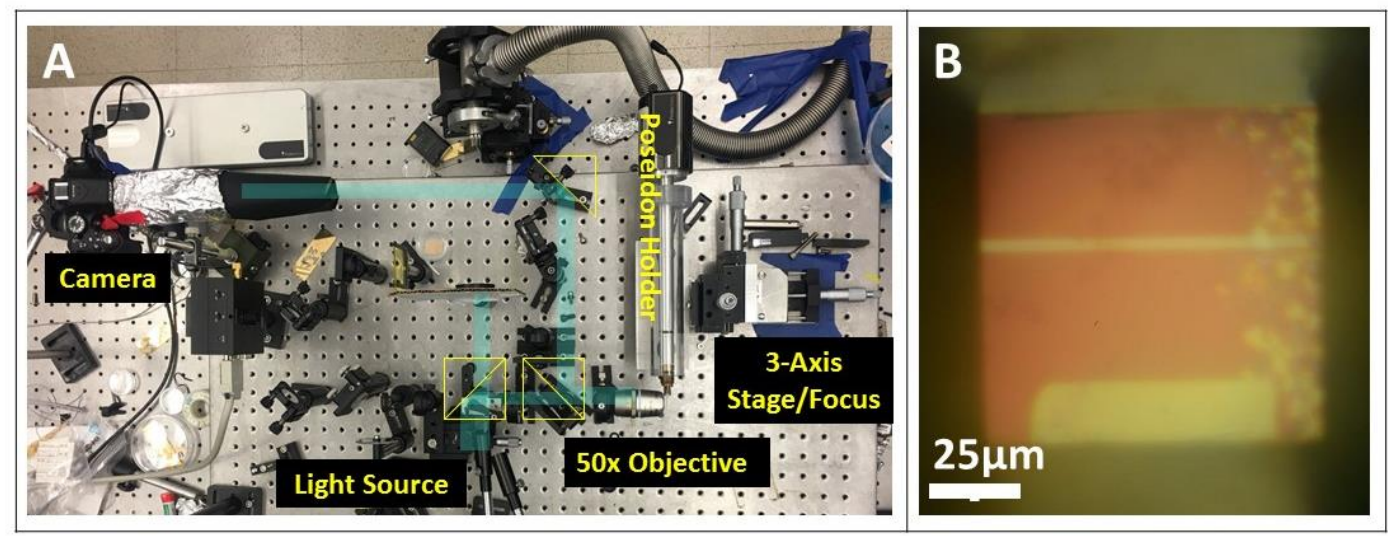

Figure 4: Optics used to image flow cell during introduction of the liquid into GFC.

\section{References:}

(1) Li, X.; Cai, W.; An, J.; Kim, S.; Nah, J.; Yang, D.; Piner, R.; Velamakanni, A.; Jung, I.; Tutuc, E.; Sanjay K. Banerjee, Luigi Colombo, Rodney S. Ruoff, Large-Area Synthesis of High-Quality and Uniform Graphene Films on Copper Foils. Science 2009, 324, 13121314. 